\title{
Avatar, Identitas dalam Cyberspace
}

\author{
Maria Nala Damayanti ${ }^{{ }^{*}}$; Elisabeth Christine Yuwono ${ }^{1}$ \\ ${ }^{1}$ Program Studi Desain Komunikasi Visual, Fakultas Seni dan Desain, Universitas Kristen Petra \\ Jalan Siwalankerto 121-131 Surabaya \\ Email's: mayadki@petra.ac.id, xine_y@petra.ac.id \\ * Korespondensi penulis
}

\begin{abstract}
Abstrak
Ketergantungan manusia akan teknologi berimplikasi pada lahirnya budaya baru dalam berkomunikasi. Budaya baru ini berkaitan dengan sosok yang ada dibalik kehadiran unsur verbal atau visual yang melakukan komunikasi dengan memanfaatkan media internet. Komunikasi yang terjalin lewat internet yang dikenal dengan cyberspace memungkinkan kehadiran seseorang dalam berbagai identitas virtual. Identitas-identitas ini muncul melalui rupa verbal dan juga visual. Ia bernama dan berrupa tetapi dapat hadir dalam segala jenis sosok yang lazim disebut avatar. Identitas seseorang dapat diwakili oleh sejumlah avatar berbeda yang mampu melakukan hubungan dengan lebih dari satu pihak dalam waktu yang hampir bersamaan. Komunikasi yang terjalin dalam cyberspace telah melewati batas jarak dan waktu. Kehadiran identitas-identitas ini jelas menunjukkan sebuah konteks model relasi yang punya tujuan tertentu. Entah model relasi sosial yang mengedepankan pertemanan, kegembiraan, rasa bermain, pikiran kritis ataupun dengan tujuan yang lain. Namun kehadiran dari identitas virtual tersebut tidak dapat begitu saja disamakan dengan identitas manusia sebagai personal dalam dunia nyata, karena identitas dalam cyberspace ini bersifat jamak dan cair, bahkan mungkin identitas tersebut dibuat dengan tujuan terselubung.
\end{abstract}

Kata kunci: Avatar; identitas; cyberspace.

\begin{abstract}
Human dependence on technology will have implications for a new culture of communication. Culture is related to the person behind the presence of elements of verbal or visual communication through internet media. Communication established via the Internet, known as cyberspace, allows the presence of a person in a variety of virtual identities. These identities emerge through verbal and visual appearances. They have names and shapes but can be present in any kind of form, commonly called avatars. The identity of a person can be represented by a number of different avatars capable of having more than one party at the same time. Communication that exists in cyberspace exceed time and space. The presence of these identities clearly indicates a relationship model that has a specific purpose. It could be a model of social relations that promote friendship, excitement, a sense of play, a critical mind or with other purposes. But the presence of such virtual identity cannot simply be equated with human beings as their personal identity in the real world, because in cyberspace, identity is plural and fluid. It can even be made with a hidden agenda.
\end{abstract}

Keywords: Avatar; identity; cyberspace.

\section{Pendahuluan}

Saat ini digitalisasi sudah menjadi bagian yang tak terpisahkan dari kehidupan kita sehari-hari, termasuk dalam hal komunikasi melalui cyberspace. Komunikasi secara verbal atau visual yang dilakukan individu-individu mendapat wadah baru yang dimungkinkan oleh keberadaan teknologi internet yang mengatasi jarak, tempat dan waktu. Secara bersamaan sejumlah orang dari berbagai belahan dunia bisa melakukan hubungan melalui teknologi internet dalam cyberspace ini.
Setiap individu bisa memiliki beberapa identitas berbeda bahkan dapat terus berubah dalam rangka menciptakan dan menjalin lebih dari satu model hubungan sosial. Teknologi tersebut seperti menjadi perpanjangan dari tubuh kita. William Gibson yang terkenal dengan novelnya Neuromancer mendefinisikan cyberspace, ('Lines of light ranged in the nonspace of the mind, clusters and constellations of data. Like city lights, receding). Hal ini merupakan kenyataan bahwa teknologi digital mengubah tubuh maupun kesadaran kita yang menjadi jaringan global yang menghubung- 
kan jutaan komputer dan orang-orang untuk bertukar informasi atau menjalin hubungan.

Cyberspace adalah ruang pribadi bagi individu untuk menciptakan fantasi-fantasi mereka sendiri atau dunia imajinatif sesuai keinginan atau ide mereka (Wood dan Smith, 2005:4-5). Hal itu dimungkinkan karena adanya Computer-Mediated Communication (CMC) sebagai integrasi teknologi komputer dengan kehidupan kita sehari-hari. CMC adalah teknologi komputer microchip yang memproses informasi dan melaksanakan perintah melalui perangkat lunak yang terintegrasi ke dalam lingkungan fisik kita, untuk menciptakan hubungan interpersonal, dan bahkan identitas pribadi.

Tulisan ini bertujuan memberikan sumbangsih pemikiran tentang identitas dalam cyberspace sebagai bahan wacana, yang keberadaannya telah akrab dan bahkan menjadi bagian dari diri kita. Untuk memahami sifat identitas dalam cyberspace dan bagaimana identitas tersebut hadir, dilakukan pengamatan terhadap forum yang ada di internet, yakni forum diskusi tentang kebebasan beragama bernama Faith Freedom International, dan game online yang berdomain di Indonesia. Identitas yang muncul pada forum tersebut akan dianalisis secara deskriptif kualitatif.

\section{Pengertian Avatar}

Satu dari tujuh prinsip cyberspace yang dikemukakan Castells dan Harraway dalam Cyberculture Theorists (Bell, 2007: 22) adalah prinsip personal visibility, dimana users dalam cyberspace harus terlihat, setidaknya dalam tingkatan yang paling rendah, oleh orang lain; meskipun kita tetap dapat memutuskan siapa yang akan terlihat atau tidak oleh kita selama kita berselancar dalam cyberspace (visible, invisible). Prinsip ini jelas berkorelasi dengan sosok yang disebut avatar. Sebuah bentuk representasi diri dalam dunia virtual.

Istilah avatar mempunyai banyak arti. Avatar sering disebutkan dalam penyebutan sosok seseorang atau sesuatu yang mewakili peran tertentu dalam komunikasi cyber. Kamus Webster menyebutkan avatar sebagai sebuah ikon yang merepresentasi seseorang yang disebarkan dalam realitas virtual (http://www.websters-online-dictionary.org). Pengertian ini sejalan dengan sebuah kamus lain yang menyebut avatar sebagai sebuah image elektronik yang hadir karena keberadaan seorang pengguna komputer (http://www.merriamwebster.com/). Contoh ini dapat ditemui dalam game berbasiskan komputer. Dengan demikian avatar adalah pengganti sosok yang ada dibalik beroperasinya komputer dalam komunikasi cyber. Ia menjadi identitas atas keberadaan sebuah entitas. Maka yang menjadi isu penting berikutnya adalah bagaimana keberadaan entitas tersebut.

\section{Body Cyber}

Para pengguna cyberspace merasakan sebuah kebebasan tertentu karena berada dalam sebuah area lain yang diharapkan tidak disentuh oleh pihak lain yang tidak mencemplungkan diri ke dalamnya. Hal ini antara lain dikemukan oleh John Perry Barlow. Barlow pernah mendeklarasikan kebebasan dalam dunia cyber lewat manifestonya yang berjudul "A Declaration of the Independence of Cyberspace" < barlow@eff.org > Davos, Switzerland pada tanggal 8 Februari 1996. Ia menyatakan bahwa cyberspace adalah medium untuk menciptakan dunia yang di dalamnya semua hal dimungkinkan. Tidak ada hak istimewa atau prasangka atas dasar ras, kekuatan ekonomi, kekuatan militer, atau tempat kelahiran. Sebuah dunia di mana siapa pun, dapat mengekspresikan keyakinannya, tanpa tekanan apa pun dan oleh siapa pun.

Hal tersebut dimungkinkan dengan prinsip yang berlaku dalam cyberspace bahwa identitas kita tidak memiliki tubuh, sehingga Barlow mendeklarasikan bahwa cyberspace kebal terhadap aturan hukum yang ditetapkan pemerintah pada umumnya. Meskipun manifesto ini lebih ditujukan kepada pemerintah, dapat disimpulkan adanya harapan bahwa cyberspace ini harus diperlakukan dengan cara dan konsep yang berbeda dari pada hal di luar itu, dan ini berkaitan erat dengan apa yang dimaksudkan dengan tubuh cyber itu sendiri.

Tubuh cyber yang populer dengan istilah body cyber membincangkan hal-hal tentang keberadaan entitas yang terwakili, antara lain oleh avatar. Ada empat hal penting dalam body cyber seperti yang dikatakan David Bell (2004). Pertama, cyberspace ini membebaskan tubuh dari basis biologisnya serta memungkinkan kebebasan baru, termasuk kebebasan untuk bereksperimen dengan aspek identitas pribadi, terutama gender. Kedua, tubuh dalam cyberculture berpusat pada perpaduan antara bio body dengan teknologi. Contohnya adalah Cyborg dan Post Human, yang tidak saja dianggap produktif tetapi juga dapat menjadi sumber masalah. Ketiga, cyborg adalah organisme cybernetic yang merupakan gabungan dari mesin dan organisme, hasil ciptaan masyarakat sebagaimana penciptaan fiksi (Harraway dalam Bell, 2004:150). Cyborg juga dikatakan sebagai ciptaan dunia 'post-gender', yang tidak berkaitan dengan 
katagori seks (Bell, 2004:150). Keempat, tubuh Post-human (simbiosis antara manusia dan teknologi) dikatakan dapat mengatasi keterbatasan fisik melalui pemanfaatan organ buatan, sehingga disebut juga sebagai langkah awal dalam era pasca evolusi (Stelarc, 2000). Contohnya adalah Automaton, Robot, Android, Cyborg, Bionic human. (Bell, Loader, Pleace and Schuler, 2004:8-9). Kesimpulannya menurut Alan Watts, teknologi harus dirancang dan dimanfaatkan tanpa mengasingkan kita dari tubuh dan dari sifat keberadaan kita, serta untuk meningkatkan kesadaran kita akan adanya wilayah baru, di mana kita dapat memahami bahwa kita adalah satu dan sedang berproses, sebagaimana alam semesta

\section{Identitas dalam Cyberculture}

Identitas yang selama ini dipahami dalam kehidupan nyata mengacu pada konsep pemikiran Barat, suatu konsep identitas yang dikenal sebagai esensialisme. Konsep tersebut memahami identitas sebagai apa yang melekat apa adanya pada diri kita ketika dilahirkan. Dengan demikian, keberadaan kita sebagai manusia adalah nyata, sehingga identitas merupakan sesuatu yang tetap dan stabil. Namun pandangan tentang identitas yang demikian telah berubah dan memunculkan cara pandang baru dalam memahami identitas yang berlawanan dengan konsep lama.

Dalam konsep yang baru, identitas dipahami sebagai sesuatu yang tidak tetap, tidak menyatu secara utuh, tidak memiliki asal usul, dan sebagainya. Secara khusus, pergeseran teori tersebut merupakan imbas dari postmodernisme dan postrukturalisme yang mempertanyakan dan terus mempertajam cara berpikir kita tentang siapakah kita. Hall (dalam Bell) mengakui hal tersebut dan mengajukan perubahan dari 'identitas', yang dipandang sarat akan paradigma lama, menjadi 'identifikasi'. Istilah baru tersebut menyiratkan adanya suatu proses, keberagaman, dan konstruksi bahwa identifikasi seseorang adalah dibuat, bergerak (mobile), dan beragam. (2001:114-115).

Pemahaman tersebut secara lebih jelas tampak ketika dihubungkan dengan teknologi, dalam hal ini cyberculture yang sudah sedemikian menyatu dalam kehidupan kita. Dengan demikian, diri atau pribadi yang fluid dan fragmented memiliki kappasitas untuk membentuk dirinya sendiri, membentuk dan mengatur ulang elemen-elemen identitas.

Donath (1999:27) mengungkapkan, identitas dalam dunia virtual bersifat ambigu. Kepribadian dan peran sosial dalam dunia nyata tidak dapat disamakan dengan dunia virtual. Identitas memegang peranan penting dalam suatu komunitas, tidak terkecuali komunitas virtual. Suatu komunitas akan selalu ditandai dengan adanya komunikasi antar anggotanya. Aspek penting dalam identitas cyber adalah bagaimana menampilkan atau menyatakan diri kepada orang lain. Pada tahap tertentu, seseorang dapat menentukan dan membatasi apa yang ingin agar orang lain ketahui tentang dirinya. Dalam dunia online, ciri-ciri yang terlihat dalam dunia nyata seperti jenis kelamin, kelompok ras, busana tidak tampak, dan sebagai gantinya teknologi internet menawarkan kemungkinan untuk mengendalikan aspek-aspek dari identitas diri sebagai pertimbangan bagi publik. (Wood dan Smith, 2005:57).

Dalam dunia nyata, prinsip yang berlaku adalah satu tubuh, satu identitas. Dengan demikian, terdapat kesatuan yang utuh dalam diri, sehingga tubuh akan mendefinisikan identitas. Namun tidak demikian halnya dengan dunia virtual. Cyberspace, yang dimunculkan dalam novel William Gibson, Neuromancer, dipahami sebagai suatu consensual hallucination sebagai pengalaman sehari-hari yang dikendalikan berjuta operator. Suatu representasi grafis data yang abstrak dari berbagai komputer sistem manusia. Kompleksitas yang tak terbayangkan. Garis-garis cahaya yang berpendar dalam pikiran, kerumunan tanpa ruang dan kumpulan data. (Gibson dalam Bell, 2007:2). Dari penjelasan Gibson tersebut dapat disimpulkan dunia virtual terdiri dari data dan informasi yang bersifat abstrak. Informasi menyebar dengan cepat dan bebas. Dengan demikian, anggota atau orang-orang yang ada di dalamnya juga memiliki sifat yang serupa, mereka menyebar, bebas dari ikatan-ikatan yang menyatukan tubuh. Sebagai implikasi dari hal tersebut, seseorang dapat memiliki beragam identitas sebanyak yang diinginkannya.

Identitas dalam konteks kehidupan online menjadi pemikiran, karena komunikasi yang ada utamanya berdasarkan teks. Hal itu berarti bahwa partisipan atau siapa saja yang berada di dalamnya memiliki kesempatan untuk menghadirkan dirinya sendiri sebagaimana yang diinginkan. (Slater dalam Bell, 2001:116). Bila seseorang menuliskan dirinya dan menjadi ada dalam cyberspace, ia dapat menciptakan dirinya, dan dapat terus diperbarui, yang terpisah dari 'daging' dalam kehidupan nyata maupun identitas fisik yang dibawanya. Dengan kata lain, identitas dalam cyberspace tidak memiliki flesh.

Menurut Amy Bruckman (1992) dalam Boler (2007:192), forum-forum berbasis teks seperti MUD (Multi-User Domain) merupakan "identity workshops", tempat di mana identitas berubahubah. Gender yang berubah-ubah merupakan contoh nyata bahwa network berada dalam proses perubahan bukan hanya bagaimana kita bekerja, 
namun bagaimana kita berpikir tentang diri kita dan juga, siapa kita. MUD memberi kesempatan orang-orang di dalamnya untuk menampilkan manifestasi diri mereka dengan berbeda-beda. (Wood dan Smith, 2005:58). Senada dengan hal tersebut, Turkle (1995) dalam Wood dan Smith (2005:58) menegaskan bahwa komputer memungkinkan penggunanya untuk mengeksplorasi peran ganda. Ia mengatakan, "Dalam ... dunia yang dimediasi oleh komputer, pribadi adalah jamak, cair dan dibentuk dalam interaksi yang berkoneksi dengan mesin; serta dibentuk dan diubah oleh bahasa".

Bahasa merupakan sarana utama dalam membangun identitas diri dan memahami identitas seseorang dalam dunia online. Gambar atau figur tertentu yang awalnya merupakan fantasi di kalangan gamers dan digunakan di antara pengguna CMC (Computer-Mediated Communication) diistilahkan sebagai avatar. Avatar merupakan representasi dari diri sendiri dalam lingkungan virtual, dengan kata lain, satu alter ego atau kepribadian. Dalam dunia maya yang tidak memiliki ruang, seseorang tidak memiliki tubuh. Yang ada hanyalah representasi dari diri sendiri, yang dikonstruksi sepenuhnya berdasarkan pilihan-pilihan individu. Seperti tulisan tangan, yang sekilas tidak memiliki banyak isyarat/tanda nonverbal, namun sang pembaca dapat menyimpulkan kualitas tentang si penulis berdasarkan sesuatu (misalnya lengkungan pada huruf-hurufnya, tekanan goresan huruf) selain isi atau maksud tulisan tersebut. Cyberspace merupakan suatu tempat di mana berbagai ungkapan dengan isyarat-isyarat yang bias berada di dalamnya, dan menunjukkan sebuah representasi baru sedang terjadi dalam konteks ini. (Wood dan Smith, 2005:60).

Untuk memperjelas pemaparan di atas, diberikan dua contoh mengenai bagaimana tubuh dan identitas berlangsung dan dipahami dalam cyberspace. Contoh pertama adalah suatu forum diskusi tentang kebebasan beragama bernama Faith Freedom International, forum Indonesia. Dan contoh kedua adalah game online yang berdomain di Indonesia.

"Faith Freedom International" merupakan sebuah forum diskusi terbuka mengenai ajaran dan kehidupan beragama. Pendiri utamanya bernama Ali Sina. Forum ini terbuka untuk siapa saja, umumnya diisi oleh para pemerhati keagamaan, namun tidak berafiliasi pada lembaga keagamaan tertentu. Forum ini telah mengalami beberapa kali ancaman untuk dibubarkan atau dipolisikan oleh pihak tertentu yang merasa dirugikan. Namun hingga kini tetap eksis dengan terus bertambahnya anggota.
Diskusi terbuka dan artikel tentang kesaksian hidup sehubungan dengan pengalaman kehidupan beragama tertentu, ternyata telah memicu emosi cukup banyak oknum beragama yang mengarah pada debat agama berbau SARA. Hal yang sulit dibicarakan secara terbuka di dunia nyata, menjadi dimungkinkan karena masing-masing penulis dapat menyampaikan idenya tanpa takut mengalami tekanan. Umumnya, mereka menampilkan dirinya dengan nama samaran, dan penyebutan lokasi yang terkesan asal-asalan, seperti yang terlihat pada contoh dibawah ini. Avatar bernama 'osho' berlokasi di Osho. Avatar berprofil kartun mirip sosok yang dikenal sebagai Yesus, bernama 'zebra cross', berlokasi di Nether-Land.

Avatar bergambar pilot zaman dulu, bernama 'Yihaa', menyebutkan lokasinya di 'between 2 world'. Mereka juga menggunakan avatar yang terkesan sekenanya, apabila coba dihubungkan dengan nama yang dimunculkan di sana. Sehubungan dengan kata-kata yang dipakai mereka seringkali bernada saling mengecam bahkan saling menghina, maka penggunaan nama lain serta lokasi tidak jelas tersebut, tentunya dimaksudkan untuk mengaburkan identitas sesungguhnya.

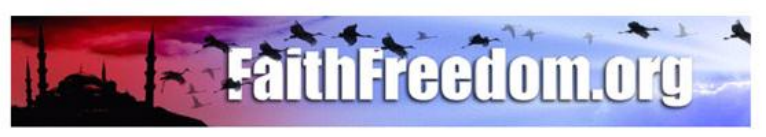

Faith Freedom International - Forum

Indonesia

Diketlola alen Faththreedon. org

Ship to cortent

AMT MAWALA (Dounload FFI

FFI Offline 122MB (Tell A Friend)

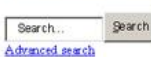

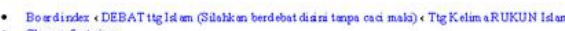

- Chenge fort aze

: $\begin{aligned} & \text { FAQ } \\ & \text { gallery } \\ & \text { Register }\end{aligned}$

Register

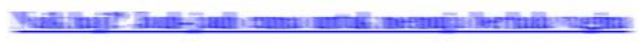

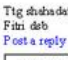

Searchnisistocit... Search

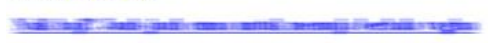

Dbyfenomena " WedApt 16, $200811: 33$ am

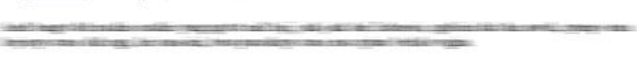

Dbyosho » Wed Apr 16, $200812: 14 \mathrm{pm}$

ketarya..
itu souvernir from $G O D$.

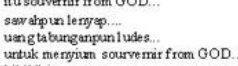

whihin

(2)

sho

Kecandun
00000

Posts: 2136 


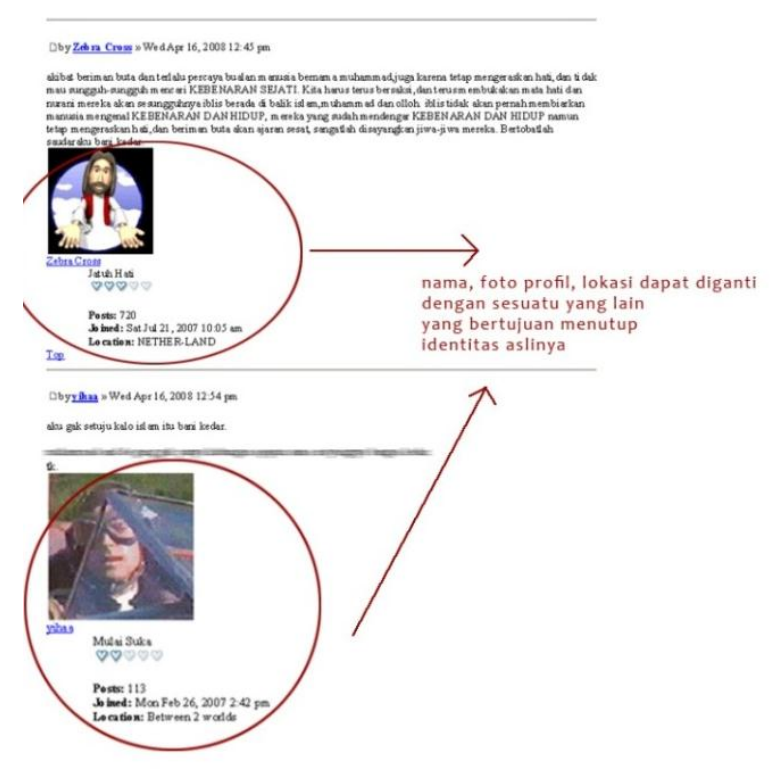

Gambar 1. Forum Faith Freedom International

Forum ini dapat terus esksis karena cyberspace sebagai media utamanya memberi peluang seluasnya kepada setiap individu untuk tampil sesuai idenya sendiri. Entah dengan tujuan keamanan seperti contoh di atas maupun untuk tujuan yang lain. Berarti tubuh yang tampil dalam forum ini bukanlah tubuh realis sebagaimana dipahami dalam dunia nyata, karena memanfaatkan jaringan komputer yang diwakili oleh data digital yang kompleks. Identitas yang ditampilkan pada forum tersebut merupakan identitas yang telah dibatasi oleh user, sehingga identitas tersebut bersifat ambigu.

Contoh kedua merupakan game online (Ragnarok) yang menyediakan sebuah 'dunia' atau ruang untuk bermain dengan cerita dan karakter yang telah disediakan. Pada game tersebut, para pemain dari berbagai tempat berkumpul dalam game tersebut. Setiap karakter yang muncul pada game screen merupakan perwakilan dari para pemain yang masih on line. Bila mereka sudah tidak on line, maka karakternya akan menghilang dari game screen.

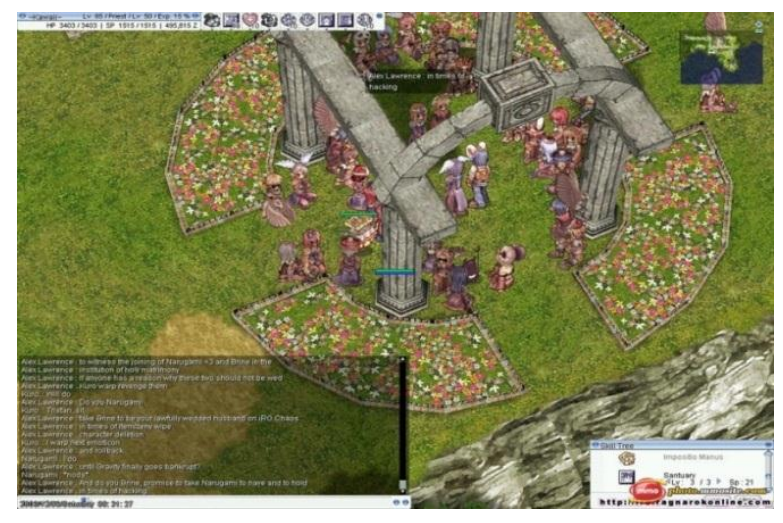

Gambar 2. Tampilan game online Ragnarok Online (RO)
Setiap pemain/user yang pertama kali bergabung dalam game tersebut akan diberi pilihan gender laki-laki atau perempuan. Setelah itu mereka dapat membuat bentuk karakter sesuai keinginan mereka dengan memilih bentuk muka, warna rambut, warna kulit, hingga jenis class dimana setiap class memiliki peran tertentu.

Ketika seseorang bermain dan melihat tampilan screen monitor, dia akan dapat melihat pemainpemain lain melalui karakter-karakter yang terdapat pada monitor. Setiap karakter tersebut juga memiliki nama, seperti Alex Lawrence, Kuro, Narugami, dsb. Berdasarkan gambaran singkat game online tersebut, nama dan tampilan karakter yang ada merupakan identitas dari pemain. Namun berbeda dengan identitas dalam dunia nyata, identitas dalam game online atau dunia virtual bersifat fluid dan jamak. Sebab banyak terjadi, ketika dihadapkan pada pilihan gender, tidak semua pemain memilih gender yang sama dengan dirinya. Ada kalanya pemain memilih gender yang berlawanan dengan aslinya, misalnya seorang laki-laki memilih gender perempuan untuk karakter yang akan dimainkannya, demikian sebaliknya.

Pemilihan tersebut memiliki alasan-alasan tertentu, seperti untuk menimbulkan belas kasihan terhadap karakter yang dipilihnya. Pada game tersebut, setiap pemain memiliki kesempatan untuk menciptakan tiga karakter yang berbeda, dalam satu server. Contoh tersebut memperjelas bahwa dalam dunia cyber, tubuh seseorang tidak lagi berupa tubuh biologis, yang hal itu memungkinkan kebebasan untuk bereksperimen dengan aspek identitas pribadi, terutama gender.

Selain itu, prinsip satu tubuh memiliki satu identitas yang berlaku dalam dunia nyata tidak berlaku lagi. Dalam dunia virtual, seseorang dapat memiliki beragam identitas sebanyak yang diinginkannya. Seseorang dapat menuliskan dirinya (dan dengan demikian ia menjadi ada dalam cyberspace), dan dapat terus diperbarui, yang terpisah dari 'daging' dalam kehidupan nyata maupun identitas fisik yang dibawanya. Dengan kata lain, identitas dalam cyberspace tidak memiliki flesh. Yang ada hanyalah representasi dari diri sendiri, yang dikonstruksi sepenuhnya berdasarkan pilihan-pilihan individu.

\section{Kesimpulan}

Cyberspace menjadi ruang baru bagi individuindividu untuk tampil dengan beragam identitas. Identitas yang biasa disebut sebagai avatar ini tidak bisa begitu saja disamakan dengan identitas 
sebagaimana realitas dunia fisik. Satu tubuh tidak berarti satu identitas atau satu avatar. Identitas sendiri kemudian menjadi jamak. Identitas virtual bisa menjadi berbeda untuk berbagai kepentingan pada suatu masa yang tertentu pula. Identitas ini dapat berakhir sewaktu-waktu ketika tidak lagi dibutuhkan. Identitas dalam cyberspace ini bisa berhubungan dengan faktor keamanan, ia juga bisa berhubungan dengan bentuk dan tujuan dari semua bentuk relasi lain yang sedang dibangun seseorang. Namun identitas yang muncul lewat avatar ini bahkan tidak punya hubungan sama sekali dengan apapun yang mungkin diduga oleh lawan bicara. Avatar bisa berbentuk apa saja.

Satu hal yang perlu digarisbawahi adalah bahwa eksistensi setiap identitas virtual atau avatar sangat bergantung kepada teknologi digital yang mengkodekan secara elektronik setiap identitas sesuai harapan pemiliknya dan menyebarkannya dalam dunia yang tidak berbatas. Identitas virtual menjadi sangat lemah karena ia bergantung penuh kepada teknologi. Tanpa teknologi, avatar tidak akan dikenal. Tanpa teknologi, identitas atas satu tubuh fisik hanya dikenal sebagai sebuah identitas.

\section{Daftar Pustaka}

Donath, Judith S. 1999. "Identity and Deception in the Virtual Community," dalam Smith dan Kollock (eds.), Communities in Cyberspace. London: Routledge.

Bell, David. 2001. An Introduction to Cyberculture. London: Routledge.

Bell, David, Brian D.Loader, Nicholas Pleace and Douglas Schuler (Ed). 2004. Cyberculture: The Key Concept. New York: Routledge.

Bell, David. 2007. Cyberculture Theorists-Manuel Castells and Donna Haraway. London: Routledge.

Bell, David. 2007. Cyberculture Theorists - Manuel Castells n Donna Harraway. New York : Routledge

Boler, Megan. 2007. "Hypes, Hopes and Actualities: New Digital Cartesianism and Bodies in Cyberspace," dalam Nayar, Pramod K. (ed.). 2010. The New Media and Cybercultures Anthology. Chichester: Blackwell.

Wood, Andrew F. and Matthew J. Smith. 2005. Online Communication : Linking Technology, Identity, and Culture. Mahwah: Lawrence Erlbaum Associates. 